\title{
O QUADRANTE VAZIO \\ Estilos de campanhas eleitorais digitais nas eleiçóes para deputados distritais em 2018
}

\section{Marisa von Bülow (i) (i)}

E-mail: vonbulow@unb.br

\section{Igor Brandão}

E-mail: ribasigor@gmail.com

(1) Professora do Instituto de Ciência Política (IPOL), Universidade de Brasília (UnB), Brasília, D.F., Brasil. Pesquisadora associada do German Institute for Global and Area Studies (GIGA), Hamburgo, Alemanha.

(2) Doutor em ciência política, Instituto de Ciência Política (IPOL), Universidade de Brasília (UnB), Brasília, D.F., Brasil.

DOI: $10.1590 / 3610613 / 2021$

\section{Introdução}

As eleições brasileiras de 2018 foram disruptivas e radicalizadas, como apontam vários analistas (Abranches, 2019; Castillo, 2018). Em parte, isto se deu pelas novas possibilidades de usos de tecnologias digitais, em paralelo a mudanças importantes na legislaçáo eleitoral, como a proibição do financiamento empresarial, a criação de um fundo de financiamento público e a diminuição do período oficial de campanha. Entre os novos usos eleitorais das tecnologias, ganharam destaque a automatização do envio de mensagens via WhatsApp e a possibilidade legal de pagar por propaganda em plataformas digitais como o Facebook, o Instagram e o Google.

Estas mudanças, aliadas ao crescimento do acesso à Internet e de seu uso para o ativismo político,

Artigo recebido em: $14 / 04 / 2020$

Aprovado em: 28/10/2020 nos levaram à expectativa de que nas eleições de 2018 as tecnologias digitais seriam utilizadas intensivamente por todos os candidatos. No entanto, como demonstramos neste artigo, nem mesmo no município com maiores níveis de acessibilidade à Internet do país - o Distrito Federal - as campanhas locais incorporaram as várias possibilidades digitais abertas de forma ampla. Os objetivos deste trabalho são mapear e analisar as diferentes práticas digitais de campanhas de parlamentares eleitos, a partir das seguintes perguntas de pesquisa: Dado um conjunto de possibilidades similares e um contexto semelhante, quais foram as escolhas dos atores? Como estas escolhas se relacionam com suas percepçóes sobre a relevância das plataformas e seus impactos? Estas perguntas são respondidas a partir da análise das estratégias das candidaturas vencedoras às eleiçóes para a Câmara Legislativa do Distrito Federal (CLDF) em 2018.

A análise confirma que todos os candidatos eleitos incorporaram estratégias digitais às suas campanhas. 
No entanto, os resultados da pesquisa mostram que não houve uma estratégia digital única. Pelo contrário: as campanhas dos (as) 25 parlamentares eleitos (as) reagiram de maneiras muito diferentes à possibilidade de pagar pelo impulsionamento de conteúdo online e também de apropriar-se dos recursos e plataformas disponíveis. A partir do cruzamento destes dois eixos - priorização de gastos em propaganda digital e amplitude de recursos digitais utilizados - propomos uma tipologia de quatro estilos digitais de campanhas eleitorais. As campanhas dispersas utilizam um conjunto amplo de plataformas, mas não priorizam os gastos com impulsionamento de conteúdo online. Já as campanhas diversificadas maximizam os usos das diferentes plataformas e ao mesmo tempo priorizam os gastos com impulsionamento de conteúdo online. As campanhas tradicionais não se destacam nem em um e nem em outro eixo. Finalmente, as campanhas concentradas priorizam gastos com impulsionamento de conteúdo online, mas não diversificam usos de recursos digitais. No caso da CLDF, a distribuição das campanhas vitoriosas de 2018 ao longo destes dois eixos mostra um "quadrante vazio": nenhuma campanha foi classificada como diversificada, ou seja, nenhum (a) deputado (a) eleito (a) deu prioridade aos gastos com impulsionamento de conteúdo online ao mesmo tempo em que utilizou uma grande diversidade de recursos digitais. Quase metade das campanhas analisadas (11 de 25) se localizam no quadrante oposto, ou seja, foram caracterizadas como tradicionais - com pouca amplitude de uso de recursos digitais e gasto proporcional reduzido (ou inexistente) com impulsionamento de conteúdo online.

Argumentamos que essa distribuição não é fruto apenas do acesso das campanhas a recursos financeiros e nem se explica totalmente pelas diferenças no perfil individual dos parlamentares, variáveis enfatizadas pela literatura (Gulati e Williams, 2013) para explicar diferentes níveis de uso de recursos digitais. Resulta, fundamentalmente, de processos dinâmicos de aprendizado dos atores em um contexto de incerteza quanto ao uso e à efetividade de novas estratégias digitais. Nas entrevistas que realizamos, parlamentares e assessores relataram divergências internas sobre a efetividade das estratégias digitais e os obstáculos para conseguir direcionar esforços para a parte digital de suas campanhas. Além disso, evidenciaram o caráter relacional do processo de apropriação de recursos digitais, no sentido de que esse processo foi em parte fruto da interação com os eleitores, que pressionaram os candidatos a ter maior presença digital.

Apresentamos a seguir uma breve revisão da literatura sobre estratégias digitais eleitorais, com foco nas análises que buscam explicar diferentes níveis de uso de estratégias digitais em eleições proporcionais locais. Posteriormente, explicamos a metodologia utilizada, apresentamos a tipologia de estilos de campanha e discutimos os resultados da pesquisa. Concluímos o artigo apresentando algumas das limitaçóes da pesquisa e possíveis passos futuros.

\section{Diversidade de Práticas Digitais Eleitorais em Contexto de Incerteza}

A literatura sobre processos eleitorais analisa o papel transformador dos usos da Internet em campanhas políticas desde a década de 1990 (Aggio, 2010; Braga e Carlomagno, 2018; Chadwick, 2017; Stromer-Galley, 2014). Este artigo contribui com o debate por meio da análise das campanhas eleitorais para o Poder Legislativo local que obtiveram sucesso no Distrito Federal em 2018. Assim, dialoga-se mais proximamente com os estudos focados nas estratégias digitais de campanhas proporcionais em âmbito local.

As transformações no ambiente de informação e nas tecnologias para a comunicação têm afetado tanto as estratégias eleitorais de candidatos como as dinâmicas de suas campanhas. Ao analisar essas mudanças, autores têm destacado o uso crescente e intensivo de uma grande variedade de ferramentas e plataformas (Stromer-Galley, 2014; Chadwick, 2017), o que neste artigo designamos por "amplitude do uso de recursos digitais”. Uma parte dessa literatura tem investigado o processo específico de incorporação de ferramentas e plataformas digitais em campanhas para o Poder Legislativo (Williams e Gulati, 2013; Gulati e Williams, 2013). Esses trabalhos têm revelado um processo de apropriação de tecnologias digitais menos linear e de menor amplitude do que os estudos focados em eleiçôes para o Poder Executivo, mesmo em países desenvolvidos com grande quantidade de recursos e amplo acesso dos eleitores à Internet. 
Em dois estudos sobre a adoção de ferramentas digitais por candidatos ao Legislativo, Williams e Gulati (2013) e Gulati e Williams (2013) analisam como um pequeno grupo de candidatos não adeptos do Facebook se diferenciou da grande maioria nas eleiçóes de 2006, 2008 e 2012 nos Estados Unidos. As autoras mostram que a difusão da ferramenta entre as campanhas neste período foi influenciada por diversos fatores (partidos, competição, recursos financeiros e nível de escolaridade nos distritos) e concluem que adoção e uso de plataformas digitais dependem de variáveis diferentes. Enquanto a propensão para adotar plataformas como o Facebook teria sido influenciada pelas taxas de adoçáo por pares ou concorrentes no mesmo estado, a maneira como estas foram utilizadas, não (Williams e Gulati, 2013). As autoras argumentam que candidatos com mandato utilizaram o Facebook mais extensivamente e argumentam que os "náoadotantes" são significativamente mais propensos a serem candidatos sem mandato, mais velhos, com poucos recursos e em corridas pouco competitivas (Gulati e Williams, 2013, p. 582-585).

No Brasil, os estudos sobre eleiçōes e internet dividem-se, de acordo com o balanço proposto por Braga e Carlomagno, em dois períodos, antes e depois das eleiçōes de 2010 (2018, p. 15). A segunda fase é caracterizada "pela queda das restriçóes legais ao uso do Internet e pelo uso crescente de diferentes recursos digitais" nas campanhas (Braga e Carlomagno, 2018, p. 15). As eleiçôes de 2018 seguiram essas duas tendências gerais, mas ampliaram de forma importante as agendas de pesquisa. Entre outros temas, a literatura que emerge do processo busca compreender a centralidade do uso do WhatsApp e o fortalecimento das candidaturas à direita do espectro ideológico (Cesarino, 2020; Nemer, 2019), a difusão de desinformaçāo e discurso de ódio na Internet como estratégias eleitorais (Santos et al., 2019; Brito Cruz et al., 2019a), e estratégias de segmentação (Evangelista e Bruno, 2019), com foco prioritário na análise das eleiçóes presidenciais.

De forma geral, estudos que analisam eleições proporcionais locais no Brasil são escassos. Além disso, náo costumam olhar para as estratégias digitais de maneira ampla, incluindo as várias plataformas e possibilidades de apropriação das tecnologias de acordo com os objetivos das campanhas. A maioria foca nos usos de uma, no máximo duas plataformas de mídia digital. Braga, Nicolás e Becher (2013a; 2013b), por exemplo, examinam as campanhas de candidatos a vereador em Curitiba, Florianópolis e Porto Alegre, nas eleiçôes de 2008, com foco no uso político dos websites de aproximadamente 1.400 postulantes. A análise conclui que práticas tradicionais predominaram nas páginas web dos candidatos, reforçando vínculos clientelistas e personalistas com o eleitorado.

Em outro trabalho, Braga (2014) avalia se o uso de mídias como o Twitter e o Facebook pode ser um preditor tanto das taxas de eleição e reeleição como das características das campanhas a vereador em capitais de estados das regióes Sul, Sudeste e Nordeste do Brasil. Ao cruzar dados sobre tipo e grau de uso das plataformas com informaçóes sobre votação dos candidatos nas eleiçóes de 2012 (p. 138), o autor argumenta que a competitividade dos candidatos foi afetada pelo uso das plataformas, o que tornou suas candidaturas mais responsivas e participativas. No entanto, conclui que o uso de novas tecnologias digitais não pode ser considerado um bom preditor do êxito e do fracasso eleitoral das candidaturas que disputaram a reeleição.

Marques e Mont'Alverne (2013), por sua vez, exploram as maneiras como 25 parlamentares da cidade de Fortaleza utilizaram o Twitter em busca da reeleição entre julho e novembro de 2012. Os autores encontram correlaçáo positiva entre a quantidade de tweets publicados e a quantidade de seguidores atraída por algumas contas, porém revelam que grande parte das candidaturas demonstrou desinteresse por empregar o Twitter em suas estratégias de comunicação política. Em outro estudo no mesmo contexto, Marques e Mont'Alverne (2016) analisam o conteúdo das mensagens enviadas pelos candidatos a seus seguidores e sua associaçáo com a filiaçáo partidária. Eles argumentam que não houve relação direta entre êxito eleitoral e o uso do Twitter nas eleiçóes para o Legislativo de Fortaleza em 2012. Não foi encontrada associação entre filiaçáo partidária e campanhas digitais, exceto em pequenos partidos de esquerda. $\mathrm{O}$ estudo sugere que a sociabilidade comunitária - entendida como relaçôes face-a-face ou interaçôes entre indivíduos afeta como a Internet é usada por campanhas locais. 
A pesquisa realizada com as candidaturas vencedoras da Câmara Legislativa do D.F. em 2018 confirma vários achados desta literatura sobre eleiçóes proporcionais, como por exemplo a pouca importância do Twitter e a continuidade da relevância das estratégias presenciais, e avança para mapear e explicar a diversidade de estilos de campanha digital. Diferenciamos as práticas digitais adotadas pelas campanhas ao longo de dois eixos: priorização e amplitude. Priorização refere-se à relação entre gastos para gerar maior alcance de publicaçóes online (impulsionamento de conteúdo) e os gastos totais declarados pelas campanhas. Amplitude referese à diversidade de iniciativas e plataformas digitais utilizadas. A tipologia que resulta do cruzamento entre priorização e amplitude refere-se especificamente à incorporação de recursos digitais pelas campanhas, diferenciando-se de outras tipologias que incluem variáveis relacionadas ao impacto, como o grau de interatividade com os eleitores (Gomes et al., 2009). Essa tipologia também se diferencia de outras propostas pela literatura por não ser cronológica. ${ }^{1} \mathrm{O}$ objetivo não é caracterizar a mudança ao longo do tempo, mas sim demonstrar como, em um mesmo contexto eleitoral, campanhas exitosas apropriaramse de maneira assimétrica e limitada dos recursos digitais disponíveis. A tipologia proposta permite visualizar tanto campanhas que apostaram fortemente no impulsionamento de conteúdo, mas não usaram outras estratégias digitais, como casos opostos, de uso intensivo de recursos digitais variados sem investimento em impulsionamento.

Para entender os processos de tomada de decisão ao longo desses dois eixos, partimos do pressuposto teórico de que os atores estudados são auto-conscientes e estratégicos, no sentido de que estáo permanentemente buscando criar ou mudar oportunidades para a ação (Jasper, 2004). Assim, as práticas adotadas não são resultado apenas das possibilidades tecnológicas ou da quantidade de recursos disponíveis, mas fundamentalmente de processos dinâmicos de aprendizado dos atores sobre as possibilidades de atuação em determinado contexto, como parte da literatura sobre usos políticos de tecnologias digitais tem argumentado (Barassi e Treré, 2012; Gerbaudo, 2012; von Bülow et al., 2019). Essa visão do processo decisório dos atores permite analisar a heterogeneidade de práticas digitais mapeadas em um contexto de incerteza quanto ao uso e à efetividade de novas estratégias digitais.

Como ensina a literatura de transiçóes para a democracia, incerteza não é algo necessariamente negativo do ponto de vista normativo. Para Przeworski (1991), incerteza deve ser parte do processo eleitoral, para que este possa ser chamado de democrático. ${ }^{2}$ Neste artigo, a incerteza não se refere aos resultados do processo eleitoral, mas sim à dificuldade dos atores de preverem os impactos das suas ações ao longo da campanha, e está diretamente relacionada às mudanças na legislação eleitoral e nas tecnologias disponíveis. Nesse sentido, é mais próxima da visão de construtivistas como Blyth (2010), que argumentam que incerteza e variação são parte constitutiva da realidade, mediada pela agência humana.

Partimos do pressuposto de que a incorporação de práticas digitais está sempre permeada pela incerteza, dada a velocidade com que inovaçôes são feitas, tanto pelas empresas de tecnologia como pelos próprios usuários. No contexto eleitoral de 2018, a essa incerteza permanente adicionou-se também a incerteza gerada pelas mudanças nas regras eleitorais.

\section{Métodos e Dados}

O Distrito Federal é a unidade da federação com o melhor nível de acesso digital, de acordo com os dados do IBGE. À época das eleiçóes de 2018, $94,1 \%$ dos domicílios do D.F. contavam com acesso à Internet, e São Paulo vinha em segundo lugar, com 87,1\% (IBGE, 2018, p. 37). O D.F. mantém a primeira posição mesmo quando os dados de acesso são cruzados com outras variáveis, como idade, ser ou não estudante e estar ou não ocupado (p. 64-73). Esta especificidade do D.F. levaria a esperar que as campanhas locais adotassem estratégias digitais como parte importante, senão prioritária, de suas campanhas. Essa expectativa seria ainda maior no caso dos deputados distritais que, diferente dos candidatos a outros cargos (deputados federais, senadores e candidatos ao Governo do Distrito Federal), possuem menor visibilidade nos programas gratuitos de rádio e de televisão. ${ }^{3}$ Não é, no entanto, o que esta pesquisa demonstra. Os dados coletados mostram presença 
assimétrica e limitada nas mídias sociais. $\mathrm{O}$ caso dos deputados distritais do D.F. caracteriza-se, nesse sentido, como um "caso crítico" (Flyvbjerg, 2006, p. 231), ou seja, que permite a seguinte formulação: se nem no D.F. houve um uso prioritário e amplo das estratégias digitais nas campanhas distritais vitoriosas, podemos esperar que o mesmo seja verdade também em outros casos de eleições legislativas locais. A análise do caso do Distrito Federal pode, portanto, iluminar outros casos em pesquisas futuras.

Inspirados em trabalhos que buscam analisar a heterogeneidade de práticas digitais adotadas por atores políticos (Barassi e Treré, 2012; von Bülow et al., 2019), utilizamos um desenho de pesquisa baseado em múltiplas técnicas de pesquisa e fontes de dados. Esse desenho permitiu a análise das estratégias digitais eleitorais a partir das várias plataformas disponíveis e das inúmeras possibilidades de uso de cada plataforma. Também permitiu analisar as relaçóes entre as práticas digitais e presenciais dos atores e, ao mesmo tempo, suas percepçóes sobre as escolhas realizadas e seus impactos. Dentre as fontes de dados estão documentos (de candidatos, do Tribunal Regional Eleitoral e de empresas que prestaram assessoria a campanhas), publicaçóes em plataformas de mídias sociais e entrevistas semiestruturadas com atoreschave. Entre outubro de 2018 e março de 2019, entrevistamos atores das $25^{4}$ campanhas exitosas para a CLDF. ${ }^{5}$ Nesse período, também foram coletados dados sobre os gastos de campanha e sobre conteúdos impulsionados pelas candidaturas no Facebook, Instagram e Google.

Os roteiros das entrevistas foram constituídos de perguntas abertas e fechadas sobre as escolhas das candidaturas acerca das atividades de campanha realizadas. Entre as questóes fechadas, os atores foram indagados sobre quais atividades online e offine haviam realizado, incluindo panfletagem, criação de grupos privados e públicos de WhatsApp, reunióes domiciliares, uso de faixas e/ou bandeiras, publicação de vídeos no Youtube, impulsionamento de conteúdo no Facebook, Google e Instagram, vaquinha eletrônica (crowdfunding) e realização de eventos para arrecadação de recursos. Foram perguntados também sobre sua percepção da importância, em uma escala entre 0 - nada relevante - e 5 - extremamente relevante
-, das seguintes plataformas: WhatsApp, Facebook, Instagram, Website, Youtube, E-mail e Twitter.

Foram indagados ainda sobre a relevância dessas plataformas para cinco objetivos de campanha: mobilizar simpatizantes, coordenar atividades, chamar para eventos, debater estratégias e conseguir votos. Mesmo que o objetivo de campanhas eleitorais seja sempre o de conseguir mais votos, a separação entre esse e os demais objetivos permitiu diferenciar o uso de plataformas digitais para atividades internas de campanha, como o debate de estratégias e a coordenação de atividades, e para as atividades voltadas para um público aberto, como as chamadas para eventos e o pedido explícito de votos.

As questóes abertas do roteiro utilizado nas entrevistas abordaram as justificativas para os usos que declararam ter feito das plataformas, considerando as mudanças das regras do jogo eleitoral e as novas possibilidades oferecidas pelas tecnologias. Enquanto os dados coletados nos documentos e nas plataformas nos permitiram mapear tanto a presença dos candidatos na Internet como seus gastos oficiais com impulsionamento de conteúdo, as entrevistas permitiram entender como as campanhas elaboraram suas estratégias digitais e obter dados das percepçóes dos atores sobre sua efetividade.

O uso de múltiplas fontes de dados possibilita, assim, enfrentar as limitaçóes metodológicas das pesquisas baseadas apenas em entrevistas qualitativas. ${ }^{6}$ Por meio da análise dos gastos e dos dados de presença nas plataformas digitais, pudemos questionar ou confirmar a consistência das informaçôes coletadas nas entrevistas. Isso foi feito de duas maneiras: a análise prévia dos dados permitiu inserir perguntas ao longo das entrevistas, com o objetivo de confirmar dados que nos pareciam inconsistentes; após as entrevistas, também buscamos confirmar informaçōes dadas pelos(as) entrevistados(as) a partir dos documentos. A tipologia de estilos de campanha proposta neste artigo é baseada nessa contraposição e complementação de dados a partir de múltiplas fontes.

Com base nas respostas sobre a relevância de diferentes tecnologias digitais para múltiplos objetivos de campanha, construímos um índice de amplitude das campanhas digitais, o qual representa o grau de diversificação de suas estratégias digitais. Dada 
a impossibilidade de medir efetivamente qual foi a relevância de cada recurso digital elencado para uma infinidade de fins possíveis, utilizamos os dados de percepção das candidaturas sobre a relevância do uso que fizeram de cada plataforma como maneira de aproximar-nos de uma medida da diversificação de suas estratégias digitais de campanha. Assim, presumimos que quem utilizou mais tecnologias para mais objetivos terá tido uma campanha digital mais diversificada. Da mesma maneira, quem utilizou menos tecnologias para menos objetivos de campanha terá implementado uma estratégia digital menos diversificada.

A partir dos dados sobre despesas de campanha declarados à Justiça Eleitoral, construímos um índice de priorização de gastos com campanha digital, que representa o quanto cada candidato priorizou gastos com impulsionamento de conteúdo. Dada a impossibilidade de distinguir confiavelmente o total de recursos destinado para atividades tradicionais (ou mesmo para atividades de marketing) daquele empregado em atividades digitais de campanha nos dados da prestaçáo de contas de cada candidato(a), decidimos utilizar um indicador de despesas claramente identificável como digital para servir como aproximação da magnitude dos dispêndios com campanha digital.

\section{O Quadrante Vazio nas Eleiçóes do Distrito Federal}

O Distrito Federal adquiriu autonomia administrativa em 1988 e acumula, desde então, competências constitucionais de municípios e estados. Assim como os estados, possui governador, deputados federais e senadores. No entanto, elege os chamados deputados distritais e não tem prefeito nem vereadores, pois lhe é vedada a subdivisão em municípios. Por essa razão, seus eleitores vão às urnas em ciclos de quatro anos, tanto para pleitos locais como nacionais, enquanto brasileiros em outras unidades da federação votam de dois em dois anos. A primeira eleição de deputados distritais ocorreu em 1990. Nas eleiçóes de 2018, foram registradas 954 candidaturas concorrendo a 24 vagas de deputado(a) distrital, ${ }^{7}$ sendo essa a mais concorrida do Brasil, com uma média de 39,75 candidatos(as) por vaga. ${ }^{8}$
Considerando a fragilidade dos partidos políticos brasileiros nas disputas locais, pesquisas têm mostrado a relevância dos gastos de campanha e do pertencimento a entidades corporativas (sindicatos, igrejas, associaçóes civis) para o êxito eleitoral de candidaturas à Câmara Legislativa do Distrito Federal (CLDF) (ver, por exemplo, Barreto, 2013). Essa configuração institucional estimula a pulverização de candidaturas, desincentiva os eleitores a buscar informaçôes sobre os(as) candidatos(as), limita suas condiçôes de aparição, e contribui para que partidos deixem os custos das campanhas a cargo das candidaturas (Barreto, 2013). A assimetria de recursos existente entre as campanhas, dessa maneira, afeta a dinâmica de escolha dos representantes pelos eleitores.

Nesse contexto, a possibilidade de realizar campanhas mais baratas, por meio de tecnologias digitais, deveria afetar a maneira como candidatos(as) combinam inúmeras estratégias de campanha. Além disso, como argumentado acima, o D.F. é a unidade da federação com o maior nível de acesso da populaçáo à Internet. Como mostraremos a seguir, no entanto, a opção pelo digital não foi um caminho percorrido de forma homogênea pelos deputados eleitos em 2018. Apesar de todos terem presença nas mídias sociais da Internet, essa presença é muito irregular e os usos das ferramentas digitais durante as campanhas foram muito variados.

O gráfico 1 mostra a presença dos parlamentares eleitos nas principais plataformas de mídia social, dois meses após a disputa eleitoral. As colunas correspondem ao número de curtidas nas páginas oficiais no Facebook (azul), ao número de seguidores no Twitter (vermelho) e no Instagram (amarelo) e, por fim, ao número de inscritos em seus canais do Youtube (verde). Os números de 1 a 25 representam as candidaturas em ordem decrescente de votos. Dos 10 candidatos mais votados (representados pelos números de 1 a 10), 6 estão entre os que tinham maior presença nas mídias sociais mapeadas. No entanto, salta à vista o fato de o mais votado (número 1 no gráfico) ter presença exígua nas mídias sociais. Não há uma correlação clara entre presença em mídias sociais e quantidade de votos.

Das 10 candidaturas com mais presença nas quatro plataformas consideradas, 8 são de incumbentes. Esse 


\section{Gráfico 1 -}

Presença dos Deputados Distritais Eleitos nas Mídias Sociais, em dezembro de 2018 (por ordem decrescente de votaçáo)

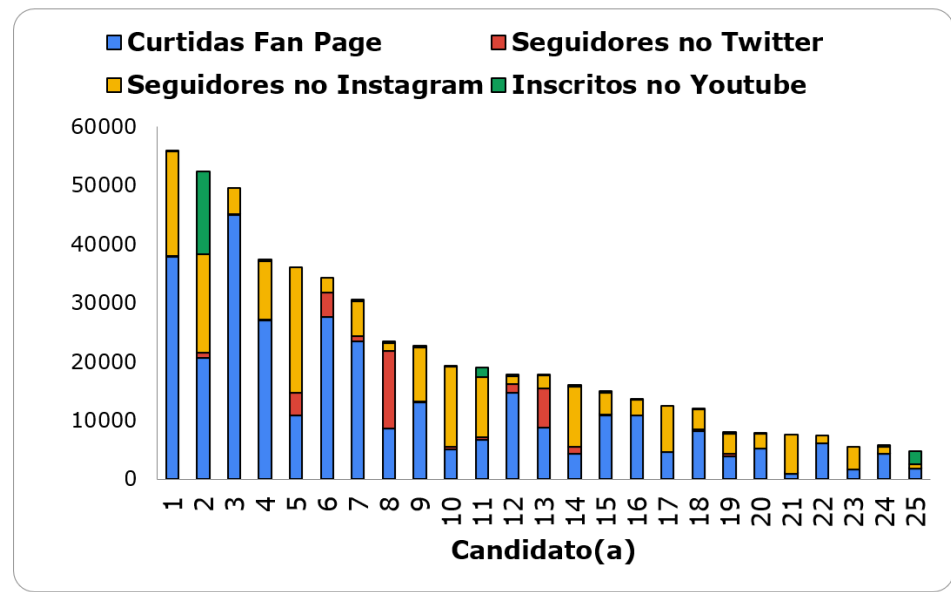

Fonte - Elaboração própria, a partir dos dados públicos das páginas oficiais dos parlamentares nas mídias sociais, coletados em 12 e 13 de dezembro de 2018.

achado confirma resultados de pesquisas em outros contextos (por exemplo, Gulati e Williams, 2013, p. 582-585), que mostram que candidatos(as) que já detinham mandato parlamentar tendem a ter maior presença digital. Essa presença é decorrente não da campanha, mas do exercício dos seus mandatos. Por outro lado, uma parte dos que se candidataram pela primeira vez tiveram que construir seu capital digital.

Finalmente, chama a atenção o fato de que não há caso de parlamentar que tenha uma presença importante em todas as plataformas. Isto é ainda mais relevante se considerarmos que os dados do Gráfico 1 já refletem o aumento do número de seguidores dos deputados decorrente da sua eleição, fato comentado em várias entrevistas realizadas no âmbito desta pesquisa. Em geral, a plataforma de preferência é o Facebook, mas nota-se a importância do Instagram, uma plataforma adotada mais recentemente pelos atores, mas que ganhou relevância ao longo do processo eleitoral (entrevistas; Sampaio et al., 2020).

A Tabela 1 complementa o Gráfico 1, ao apresentar informaçôes mais detalhadas não apenas sobre a presença dos candidatos nas plataformas digitais, mas também sobre os usos que fazem delas. Note-se, por exemplo, que apesar de $80 \%$ dos parlamentares terem conta no Twitter, apenas 35\% as utilizaram para enviar mensagens nos três meses anteriores às eleições. Também chama a atenção que apenas 8 dos 25 eleitos tinham mais de 200 inscritos em seus canais de YouTube. De forma geral, portanto, podemos afirmar que os parlamentares eleitos procuram estar presentes em várias plataformas, mas essa presença é limitada e assimétrica.

Os parlamentares eleitos utilizaram estratégias digitais para conseguir votos, mas não abriram mão de realizar atividades face-a-face. O Gráfico 2 mostra as atividades realizadas pelas campanhas durante a corrida eleitoral para as cadeiras da CLDF em 2018, com base em dados coletados nas entrevistas feitas com parlamentares e assessores. Com exceção de uma campanha, as demais utilizaram a tradicional "panfletagem". Da mesma maneira, a maioria substancial das campanhas utilizou "grupos de WhatsApp", "faixas e/ou bandeiras", "vídeos no Youtube" e "impulsionamento no Facebook". Por outro lado, apenas uma das campanhas declarou ter utilizado o GoogleAds, enquanto onze realizaram algum tipo de "crowdfunding" e apenas seis organizaram "eventos para captar recursos" presencialmente. Foi grande a diversidade das estratégias utilizadas, tanto no que se refere à presença e ao engajamento orgânicos nas plataformas de mídias sociais, como no que tange ao impulsionamento de publicaçôes e pagamento de propaganda. 


\section{Gráfico 2 -}

Atividades Realizadas pelas Campanhas Exitosas à Câmara Legislativa do Distrito Federal em 2018

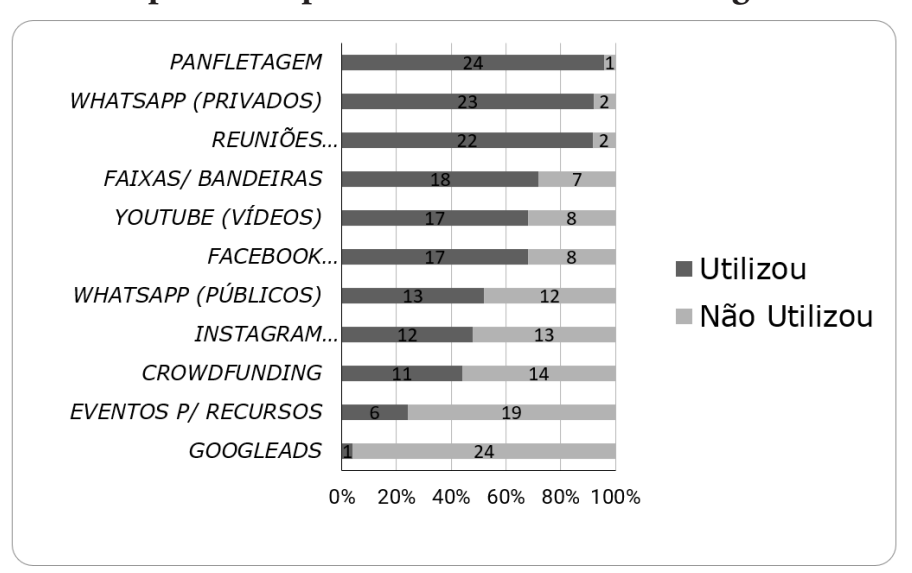

Fonte - Entrevistas com parlamentares e assessores.

Tabela 1 -

Presença dos Deputados Distritais Eleitos nas Mídias Sociais, em dezembro de 2018

\begin{tabular}{cl}
\hline Plataformas & \multicolumn{1}{c}{ Uso } \\
\hline Websites & $92 \%(\mathrm{n}=23)$ possuem site ou blog. \\
\hline Twitter & $\begin{array}{l}80 \%(\mathrm{n}=20) \text { têm conta no Twitter. Destes, 35\% }(\mathrm{n}=13) \text { postaram mensagens entre agosto e } \\
\text { outubro de 2018. }\end{array}$ \\
\hline YouTube & $\begin{array}{l}86 \%(\mathrm{n}=21) \text { detêm canal no YouTube. Destes, 38\% }(\mathrm{n}=8) \text { tinhham mais de } 200 \text { inscritos e } \\
\text { alcançaram pelo menos 1.000 visualizaçóes em seus canais. }\end{array}$ \\
\hline Facebook (perfil) & $100 \%(\mathrm{n}=25)$ possuem perfil no Facebook. \\
\hline Facebook (Fanpage) & $\begin{array}{l}100 \%(\mathrm{n}=25) \text { possuem página no Facebook. Destes, apenas 44\% }(\mathrm{n}=11) \text { têm mais de 10.000 } \\
\text { curtidas. }\end{array}$ \\
\hline Instagram & $\begin{array}{l}100 \%(\mathrm{n}=25) \text { possuem contas no Instagram. Destes, aproximadamente 44\% (n=11) têm mais de } \\
5.000 \text { seguidores. }\end{array}$ \\
\hline
\end{tabular}

Fonte - Elaboração própria, a partir dos dados das contas oficiais dos atores nas plataformas de mídias sociais, coletados em 12 e 13 de dezembro de 2018.

Embora a criação de grupos privados de WhatsApp tenha sido realizada por vinte e três campanhas, apenas treze declararam ter criado os chamados grupos públicos (cujos links são disseminados de maneira aberta para quem quiser aderir). Alguns dos entrevistados inclusive declararam desconhecer a possibilidade de uso de grupos públicos para fins de campanha. Ficaram claras também a importância atribuída ao "corpo-a-corpo" (panfletagem, uso de faixas/bandeiras nas ruas) e sua vinculação mais ou menos intencional com as atividades digitais. Bom exemplo da vinculaçấo entre açóes presenciais e digitais foi dado pela descrição do que acontecia em reuniōes presenciais, realizadas por quase todas as candidaturas (22). Vários entrevistados afirmaram ter sido esta a principal forma para coletar dados dos eleitores e, assim, manter com eles contato via WhatsApp.

Os dados apresentados no Gráfico 3 mostram as percepçóes dos entrevistados sobre a relevância das diferentes plataformas digitais. WhatsApp e Facebook foram consideradas plataformas "muito relevantes" por quase $100 \%$ dos interlocutores da pesquisa, enquanto o Instagram foi definido como tal por mais de $75 \%$ deles. Os dados corroboram a pouca importância dada pelas candidaturas exitosas ao YouTube, ao Twitter, aos E-mails e aos Websites, e ajuda a compreender a baixa presença ou o pouco uso dessas plataformas pelos parlamentares (Gráfico 1; Tabela 1). Nas entrevistas também foi 


\section{Gráfico 3 -}

Relevância das Plataformas para as Candidaturas Exitosas à Câmara Legislativa do Distrito Federal em 2018

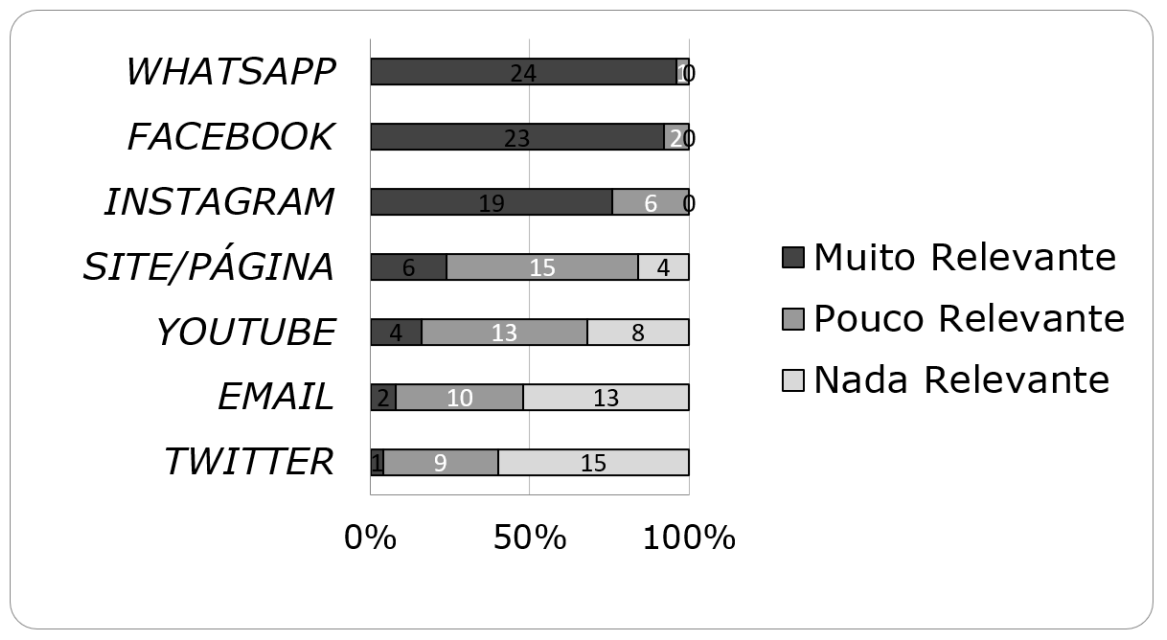

Fonte - Entrevistas com parlamentares e assessores.

Tabela 2 -

Percepçáo Média dos Atores sobre a Relevância das Plataformas Selecionadas de acordo com Objetivos, em uma escala de 0 (nada relevante) a 5 (extremamente relevante)

\begin{tabular}{|c|c|c|c|c|c|}
\hline \multirow[b]{2}{*}{ Plataforma } & \multicolumn{5}{|c|}{ Objetivos } \\
\hline & $\begin{array}{c}\text { Mobilizar } \\
\text { simpatizantes }\end{array}$ & $\begin{array}{l}\text { Coordenar } \\
\text { atividades }\end{array}$ & Chamar eventos & $\begin{array}{c}\text { Debater } \\
\text { estratégias }\end{array}$ & Conseguir votos \\
\hline Facebook (página) & 4,4 & 2,7 & 3,6 & 2,4 & 4,2 \\
\hline Facebook (grupos) & 2,5 & 1,8 & 2,2 & 1,6 & 2,4 \\
\hline WhatsApp (g. privados) & 4,5 & 4,6 & 4,6 & 3,9 & 4,2 \\
\hline WhatsApp (g.públicos) & 2,8 & 1,8 & 2,6 & 1,8 & 2,7 \\
\hline WhatsApp (listas) & 3,3 & 3,1 & 3,4 & 2,7 & 3,5 \\
\hline Instagram & 4,4 & 2,6 & 3,8 & 2,3 & 4,0 \\
\hline Website & 3,0 & 2,0 & 2,4 & 1,8 & 2,9 \\
\hline YouTube & 2,2 & 1,6 & 2,1 & 1,6 & 2,3 \\
\hline Email & 2,0 & 1,9 & 1,7 & 1,6 & 1,9 \\
\hline Twitter & 1,6 & 1,3 & 1,6 & 1,4 & 1,6 \\
\hline
\end{tabular}

Fonte - Elaboração própria, a partir de dados de entrevistas com parlamentares e assessores. Em negrito, os valores superiores a 4.

possível questionar a relevância de plataformas cujos dados não são públicos, em especial o WhatsApp. Aqui houve consenso: o WhatsApp foi fundamental. Nenhuma candidatura o considerou irrelevante. Ao mesmo tempo, páginas na Internet e e-mail foram avaliados, de forma geral, como tendo sido pouco ou nada relevantes. Destaca-se que apenas uma candidatura considerou o Twitter "muito relevante", diferentemente do que parece ter ocorrido na disputa presidencial, mas confirmando achados de pesquisas locais anteriores (Marques e Mont'Alverne, 2013).
Analisados em conjunto, os dados dos Gráficos 1, 2 e 3 permitem, portanto, afirmar que as candidaturas vencedoras da corrida eleitoral para a CLDF em 2018 apostaram fortemente no WhatsApp, no Facebook e, em menor medida, no Instagram, em detrimento de websites, mensagens por e-mail, contas no Twitter e canais no YouTube. Algo interessante a notar, no entanto, é uma certa disparidade entre o que é considerado relevante e a capacidade dos parlamentares de terem uma visibilidade coerente com essa percepção da relevância. No caso do Facebook, 
por exemplo, seis dos vinte e cinco parlamentares tinham menos de 5 mil seguidores nas suas páginas oficiais e apenas dois tinham mais de 30 mil seguidores (ver Gráfico 1), dois meses após as eleiçóes.

Questionamos os entrevistados também sobre a relevância das plataformas para cinco objetivos de campanha: mobilizar simpatizantes, coordenar atividades de campanha, chamar para eventos, debater estratégias e conseguir votos. Mais especificamente, perguntamos sobre as funçóes das plataformas, em especial nos casos do WhatsApp e do Facebook.

A Tabela 2 permite avaliar com maior precisão, portanto, a relevância dada pelos interlocutores às diferentes funçóes das plataformas, de acordo com alguns objetivos-chave de campanha. Os dados confirmam resultados de pesquisas que estudam os usos das plataformas digitais por organizaçóes de movimentos sociais, que mostram que as diferentes arquiteturas das plataformas têm impacto nos usos realizados pelos atores (von Bülow et al, 2019). Essas organizaçôes, assim como os parlamentares eleitos, utilizam pouco as páginas no Facebook ou as contas no Twitter para debate de estratégias e coordenação. Essas atividades se dão por meio de grupos privados. No passado, grupos fechados ou secretos do Facebook; atualmente, grupos no WhatsApp.

No caso do WhatsApp, questionamos separadamente pela relevância de grupos públicos, grupos privados e listas de transmissáo. Os grupos privados foram considerados os mais relevantes, especialmente para coordenar atividades de campanha e chamar para eventos, mas também para mobilizar simpatizantes e conseguir votos. Já os grupos públicos, que ganharam grande visibilidade nas discussóes das campanhas presidenciais, não foram percebidos como importantes pelos entrevistados. As listas de transmissão por WhatsApp foram relevantes, mas também em menor medida que os grupos privados. Essa diferença se deve, em parte, à natureza de cada ferramenta. Enquanto nas listas de transmissão os emitentes necessariamente precisam ter os números dos receptores registrados em seus aparelhos, nos grupos as pessoas recebem mensagens sem necessariamente terem seus números gravados pelo emitente. Finalmente, as páginas do Facebook e do Instagram foram consideradas muito relevantes, mas não para alcançar todos os objetivos.
Foram consideradas importantes sobretudo para mobilizar simpatizantes e conseguir votos. Na seção seguinte, apresentamos dados sobre o uso dessas plataformas para impulsionamento de conteúdo.

\section{Impulsionamento de Conteúdo}

A lei 13.488, de 2017, inovou ao permitir que candidatos, partidos ou coligaçóes contratassem serviços de "impulsionamento de conteúdo por provedores de aplicaçóes de Internet" . ' Nos termos da Resolução 23.551 do Tribunal Superior Eleitoral (TSE), "impulsionamento de conteúdo" consiste no "mecanismo ou serviço que, mediante contratação com os provedores de aplicação de internet, potencialize o alcance e a divulgação da informação para atingir usuários que, normalmente, não teriam acesso ao seu conteúdo" (TSE, 2017). Além das plataformas de mídias sociais, a Justiça Eleitoral incluiu os "conteúdos resultantes de aplicaçóes de busca na internet [ex Google]" (Ibidem). O “impulsionamento" permite, portanto, que a(o) candidata(a) pague para exibir seus anúncios a segmentos específicos de pessoas. ${ }^{10}$

A Tabela 3 mostra informaçóes sobre votos e gastos das campanhas (valor total e valor gasto com impulsionamento de conteúdo). A importância dada pelos entrevistados às páginas do Facebook e do Instagram, assim como a quantidade maior de seguidores no Facebook, em comparação com as demais (ver Gráfico 2), nos levariam a esperar que as campanhas tivessem feito uso intensivo da possibilidade de pagar por propaganda nessas plataformas. Uma vez mais, os dados mostram que não foi exatamente isso o que ocorreu.

De acordo com as prestaçóes de contas oficiais apresentadas ao Tribunal Regional Eleitoral, nada menos do que sete parlamentares (entre eles os dois mais votados) declararam não ter gasto nada com impulsionamento de conteúdo. Outros oito gastaram menos de $5 \%$ do seu orçamento total em contratos com a empresa que representa o Facebook Brasil. A exceção é o Deputado Donizet (PSL), que declarou ter gasto apenas dez mil reais, sendo a totalidade destes gastos com impulsionamento no Facebook. Metodologia similar à deste artigo foi utilizada pelo InternetLab para analisar a relevância 
Tabela 3 -

Gastos Oficiais dos Deputados Distritais Eleitos, total e com impulsionamento na Internet (\%)

\begin{tabular}{|c|c|c|c|c|c|}
\hline \multirow{3}{*}{ Nome } & \multirow{3}{*}{ Partido } & \multirow{3}{*}{ Votos } & \multicolumn{3}{|c|}{ Gastos (R\$) } \\
\hline & & & \multirow{2}{*}{ Total } & \multicolumn{2}{|c|}{ Impulsionamento } \\
\hline & & & & Total & $\%$ \\
\hline Martins Machado & PRB & 29.457 & $101.959,45$ & - & 0 \\
\hline Fernando Fernandes & PROS & 29.420 & $56.882,61$ & - & 0 \\
\hline Reginaldo Veras & PDT & 27.998 & $56.924,75$ & $3.600,00$ & 6,32 \\
\hline Rafael Prudente & MDB & 26.373 & $713.497,32$ & $4.000,00$ & 0,56 \\
\hline Rodrigo Delmasso & PRB & 23.227 & $458.071,21$ & - & 0 \\
\hline Chico Vigilante & $\mathrm{PT}$ & 20.975 & $129.014,95$ & $22.500,00$ & 17,44 \\
\hline Robério Negreiros & PSD & 18.819 & $827.723,27$ & $70.430,00$ & 8,51 \\
\hline Agaciel Maia & $\mathrm{PR}$ & 17.715 & $959.268,13$ & $6.761,79$ & 0,70 \\
\hline José Gomes & PSB & 16.537 & $167.396,76$ & $20.905,00$ & 12,49 \\
\hline Arlete Sampaio & $\mathrm{PT}$ & 15.537 & $153.679,02$ & $6.197,32$ & 4,03 \\
\hline Cláudio Abrantes & PDT & 14.238 & $168.247,00$ & $13.500,00$ & 8,02 \\
\hline Jorge Vianna & Podemos & 13.070 & $162.622,63$ & $3.000,00$ & 1,84 \\
\hline Jaqueline Silva & PTB & 13.044 & $247.859,85$ & - & 0 \\
\hline Iolando Almeida & PSC & 13.000 & $59.583,73$ & - & 0 \\
\hline Eduardo Pedrosa & PTC & 12.806 & $802.306,00$ & $5.000,00$ & 0,62 \\
\hline João Cardoso & Avante & 12.654 & $29.614,00$ & - & 0 \\
\hline Roosevelt Vilela & PSB & 12.257 & $113.535,88$ & $3.177,66$ & 2,8 \\
\hline Telma Rufino & PROS & 11.715 & $377.857,33$ & $1.000,00$ & 0,26 \\
\hline Joao Hermeto & MDB & 11.552 & $120.070,81$ & - & 0 \\
\hline Fábio Felix & PSOL & 10.955 & $63.600,40$ & $4.000,00$ & 6,29 \\
\hline Valdelino Barcelos & $\mathrm{PP}$ & 9.704 & $216.937,29$ & $10.000,00$ & 4,61 \\
\hline Daniel Donizet & PSL & 9.128 & $10.000,00$ & $10.000,00$ & 100 \\
\hline Júlia Lucy & Novo & 7.655 & $28.397,00$ & $3.000,00$ & 10,56 \\
\hline Reginaldo Sardinha & Avante & 6.738 & $88.100,00$ & $10.000,00$ & 11,35 \\
\hline Leandro Grass & Rede & 6.578 & $30.507,47$ & $1.400,00$ & 4,59 \\
\hline
\end{tabular}

dos gastos com anúncios políticos dos candidatos eleitos a deputado(a) federal em 2018. Nesse caso, uma proporçáo ainda menor declarou à justiça federal ter utilizado a ferramenta (apenas a metade). Por outro lado, o gasto declarado dos que a utilizaram é, como no caso dos distritais, pequeno em comparaçáo com os gastos totais (Kira et al., 2018). ${ }^{11}$ Também no nível federal, no entanto, a média utilizada na comparação esconde casos de parlamentares eleitos para os quais o impulsionamento de conteúdo foi fundamental: Major Vitor Hugo (PSL-GO) e Gilson Marques (NOVO-SC) gastaram, respectivamente, 65 e 55\% de suas despesas de campanha com impulsionamento (Kira et al., 2018, p. 12).
Como argumentam Katharine Dommett e Sam Power na sua análise sobre gastos de campanhas britânicas no Facebook, os significados desses dados têm que ser interpretados com cautela (2017, p. 263), considerando as especificidades dessa modalidade de despesa. Por exemplo, valores similares gastos pelo mesmo ator em diferentes momentos podem ter impacto muito variado. No caso do Facebook, o sistema de leiláo utilizado pela plataforma implica que o mesmo gasto pode náo necessariamente pagar pelo mesmo número de impressóes nas telas dos internautas (Dommett e Power, 2019, p. 263). Por exemplo, o usuário informa o montante que pretende investir no impulsionamento de conteúdo e, a partir disso, 
a plataforma obtém o maior número de publicações impulsionadas por aquela quantia. Note-se que as publicaçóes não possuem preço fixo, e podem mudar de valor diariamente. Nessa lógica, a exibição dos conteúdos impulsionados pode ter alcance variável, inclusive ser interrompida, e o recurso investido devolvido ao anunciante caso o resultado esperado não seja alcançado. Além disso, o sistema de leilão avalia não apenas o valor que os atores estão dispostos a pagar, mas também compara a probabilidade de engajamento de cada peça publicitária.

A Tabela 4 mostra informações sobre o desempenho dos impulsionamentos das dezoito campanhas que os realizaram. Percebe-se que o valor investido por cada candidatura não está correlacionado com o número de usuários alcançados. As colunas que mostram o total de publicaçóes com impulsionamento e as faixas de público alcançado demonstram justamente isso. Algumas candidaturas investiram valores distintos, mas atingiram a mesma "impressão". As impressões medem a frequência em que os anúncios apareceram pela primeira vez na tela para o público-alvo.

\section{Estilos de Campanhas Eleitorais Digitais}

A tipologia de estilos de campanhas eleitorais digitais proposta neste artigo refere-se especificamente à relevância e variedade de usos dos recursos digitais disponíveis pelas campanhas. O Gráfico 4 apresenta quatro estilos de campanhas eleitorais, a partir de dois eixos: a priorização de gastos digitais (eixo $\mathrm{x})^{12} \mathrm{e}$ a amplitude dos usos de plataformas digitais (eixo y). ${ }^{13} \mathrm{O}$ primeiro quadrante, no qual nenhuma campanha se localiza, retrata as campanhas diversificadas, que priorizam gastos com as tecnologias digitais e maximizam seus usos para diferentes objetivos. O segundo retrata as campanhas dispersas, que diversificam o uso de plataformas, mas não priorizam seus gastos com tecnologias digitais. $\mathrm{O}$ terceiro retrata as campanhas tradicionais, que não priorizam gastos com tecnologias

Tabela 4 -

Total de publicaçóes com impulsionamento de conteúdo, faixa de público alcançado e período ativo, por candidatura

\begin{tabular}{|c|c|c|c|c|}
\hline \multirow{3}{*}{ Candidato(a) } & \multicolumn{4}{|c|}{ Publicaçóes Impulsionadas } \\
\hline & \multirow{2}{*}{ Total } & \multicolumn{2}{|c|}{ Faixa de Usuários Alcançados (em mil) } & \multirow{2}{*}{$\begin{array}{c}\text { Período Ativo } \\
\text { (2018) }\end{array}$} \\
\hline & & Menor & Maior & \\
\hline Reginaldo Veras & 10 & 10 a 50 & 100 a 200 & $21 / 09$ a $06 / 10$ \\
\hline Rafael Prudente & 64 & $<1$ & 100 a 200 & $11 / 09$ a $06 / 10$ \\
\hline Chico Vigilante & 28 & $<1$ & 200 a 400 & $18 / 09$ a $07 / 10$ \\
\hline Robério Negreiros & 96 & 1 a 5 & 100 a 200 & $03 / 09$ a $10 / 10$ \\
\hline Agaciel Maia & 13 & 1 a 5 & 100 a 200 & $15 / 09$ a $05 / 10$ \\
\hline José Gomes & 74 & $<1$ & 100 a 200 & 04/09 a 07/10 \\
\hline Arlete Sampaio & 12 & $<1$ & 100 a 200 & $10 / 09$ a $06 / 10$ \\
\hline Cláudio Abrantes & 95 & $<1$ & 50 a 100 & $28 / 08$ a $06 / 10$ \\
\hline Jorge Vianna & 30 & 1 a 5 & 10 a 50 & $25 / 09$ a $06 / 10$ \\
\hline Eduardo Pedrosa & 12 & $<1$ & 100 a 200 & $04 / 10$ a $06 / 10$ \\
\hline Roosevelt Vilela & 61 & $<1$ & 10 a 50 & $04 / 09$ a $06 / 10$ \\
\hline Joáo Hermeto & 46 & $<1$ & 10 a 50 & $02 / 09$ a $04 / 10$ \\
\hline Fábio Felix & 61 & $<1$ & 10 a 50 & $04 / 09$ a $07 / 10$ \\
\hline Valdelino Barcelos & 27 & $<1$ & 100 a 200 & $20 / 09$ a $12 / 10$ \\
\hline Daniel Donizet & 80 & $<1$ & 100 a 200 & $05 / 09$ a $30 / 12$ \\
\hline Júlia Lucy & 68 & $<1$ & 50 a 100 & $19 / 09$ a $12 / 10$ \\
\hline Leandro Grass & 25 & $<1$ & 10 a 50 & $24 / 09$ a $06 / 10$ \\
\hline
\end{tabular}

Fonte - Elaboração própria, a partir de dados da Biblioteca de Anúncios disponibilizada pelo Facebook em: https://www. facebook.com/ads/library/?active_status=all\&ad_type=political_and_issue_ads\&country=BR, acessado em 30/12/2018. 


\section{Gráfico 4 - \\ Distribuição das Campanhas Distritais Vitoriosas, de acordo com amplitude de usos de plataformas digitais e priorizaçáo de gastos com impulsionamento digital}

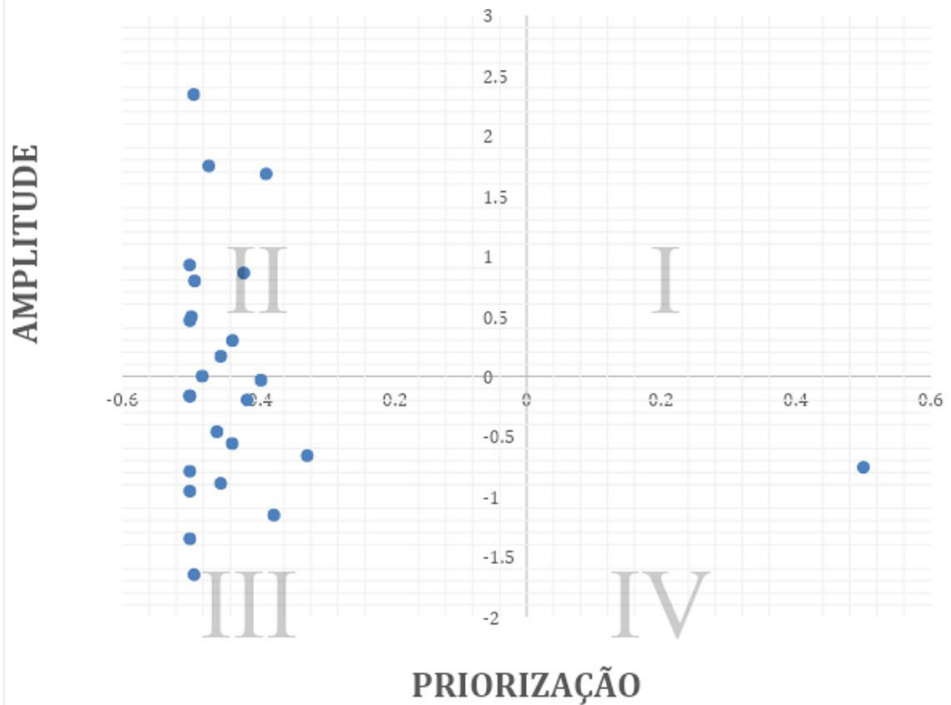

Fonte - Tribunal Superior Eleitoral, dados disponíveis em: http:/divulgacandcontas.tse.jus.br/divulga/\#/municipios/2018/2022802018/ DF/candidatos, acessado em 13/12/2019; entrevistas.

digitais nem diversificam seus usos. Finalmente, o quarto retrata as campanhas concentradas, que priorizam gastos com tecnologias digitais, mas não diversificam seus usos.

O gráfico 4 mostra a concentração de casos nos quadrantes II e III, em cada um dos quais encontramos exemplos de campanhas que declararam oficialmente ter gastado muito e pouco. No quadrante II, apresentam-se as campanhas dispersas, como a de Rafael Prudente, a quarta mais cara $(\mathrm{R} \$ 713.497,00)$, e de Julia Lucy, a segunda mais barata $(\mathrm{R} \$ 28.397,00)$ entre as eleitas (ver Tabela 3). No quadrante III, encontram-se as campanhas tradicionais, como as de João Cardoso, a terceira mais barata $(\mathrm{R} \$ 29.614,00)$, e de Eduardo Pedrosa, a terceira mais cara $(\mathrm{R} \$ 802.306,00)$ entre as vencedoras (ver Tabela 3). Ambas focaram suas açóes em atividades que chamaram de "corpo a corpo" e "sola de sapato", embora também tenham feito uso de algumas estratégias digitais. No quadrante IV, situa-se a estratégia de Daniel Donizet, classificada como uma campanha concentrada.

Por fim, destaca-se o "quadrante vazio" (I), no qual nenhuma das campanhas à CLDF foi classificada. Nenhuma das campanhas de 2018 priorizou investimentos em impulsionamento digital e ao mesmo tempo diversificou os usos de plataformas digitais.

\section{Escolhas Digitais em Contexto de Incerteza}

Quanto gastar com estratégias digitais? Vale a pena pagar para fazer propaganda em mídias sociais, e, caso sim, como fazê-lo? Em que medida é necessário e viável ter presença significativa nas várias plataformas? É preciso inovar ou é melhor manter estratégias já conhecidas e testadas? Essas e outras perguntas tornaram-se parte das reunióes de planejamento de todas as campanhas eleitorais, mas foram respondidas de maneiras muito diferentes pelos deputados distritais eleitos em 2018.

De forma geral, os entrevistados relataram muita dificuldade para ter uma presença digital sistêmica, ou seja, que vinculasse os conteúdos das campanhas nas diferentes plataformas de forma coerente. Como mostram os dados acima, as campanhas concentraram-se fundamentalmente nos usos do WhatsApp, Facebook e Instagram, sendo que tanto WhatsApp como Instagram ganharam maior relevância ao longo da campanha, em 
detrimento do YouTube. Os entrevistados explicaram que o YouTube foi substituído por plataformas de uso mais fácil ou mais relevantes, como o Instagram e o WhatsApp, e também mencionaram a incapacidade das campanhas de abarcar uma grande diversidade de plataformas:

Essa parte do candidato extrovertido, conversando com as pessoas, a gente fez muito no Instagram stories. ... Isso supriu um pouco a necessidade de ter um canal (no YouTube). Foi uma alternativa boa, que era muito mais simples. Dentro do stories você consegue editar, colocar emoji, gif, direto do celular, é muito mais rápido e tranquilo. (Entrevista 13, 2018)

A gente explorou pouco o YouTube... a gente substituiu [o YouTube pelo WhatsApp], na eleição passada o WhatsApp náo teve um quinto da importância que teve agora. (Entrevista 8, 2018)

Eu encerrei o YouTube, não ia ter conteúdo nem braço, foi uma das primeiras atitudes que eu tomei. (Entrevista 6, 2018)

As estratégias digitais não foram impactadas apenas pelo cálculo estratégico unidirecional dos candidatos e seus assessores, mas também ocorreu por iniciativa dos eleitores ao longo do processo eleitoral. Por exemplo, uma deputada que tinha uma equipe digital pequena e altamente dependente do trabalho voluntário, relata que, durante atividades de rua, os eleitores impunham o digital na campanha:

Olha o que acontecia muito: a gente tirava uma foto na rua. Se a gente não postasse aquela foto, as pessoas nos cobravam nas nossas redes. Teve um momento em que a gente teve que se adaptar $\mathrm{a}$ isso. A gente não dava conta de postar de todo mundo, e dava ciúme. (Entrevista 26, 2019)

Além das estratégias digitais serem dinâmicas e relacionais, argumentamos também que nas eleiçôes de 2018 a incerteza teve peso particularmente forte nas explicaçóes das estratégias em geral, e em particular para explicar o uso pouco intensivo do impulsionamento de conteúdo no Facebook e no Instagram, apesar da importância dada a essas plataformas. A própria definição legal de "impulsionamento de conteúdo", criticada por muitos por ser vaga (Brito Cruz et al., 2019b), gerou dúvidas nas campanhas sobre o que poderia ou não ser feito e, posteriormente, sobre como seria a prestação de contas. Além disso, o próprio Facebook - alvo preferencial dos anúncios pagos pelos candidatos distritais - foi fonte de incertezas, que se somou à inexperiência dos atores no uso da ferramenta de anúncios.

As dificuldades enfrentadas para obter informaçóes e para entender os procedimentos legais e as regras definidas foram explicadas pelos entrevistados da seguinte maneira:

Todo mundo sofreu com o impulsionamento no Face (...) a gente (estava) desesperado porque o Face demorou muito. Não sei se a campanha de 45 dias é positiva. Se você tem grana, contrata cabos eleitorais, fica conhecido na cidade e pega voto. Quem não tem, como faz? (Entrevista 5, 2018)

A gente teve um pouco de dificuldade com a burocracia (...) e é muito difícil dentro do Facebook você fazer qualquer coisa sem pagar e acertar em como, para quem você está colocando esse dinheiro para atingir (...) a gente levou um tempo no período de pré campanha para estudar patrocínio, para investigar um pouco mais como funcionava a formação de público.... (Entrevista $1,2018)$

Foi muito difícil mexer com o gerenciamento de anúncio do Face. Até que chegou um cara que trabalhava com um deputado federal e sentei com ele um dia inteiro. Isso foi depois de duas semanas eu tentando fazer. Em uma campanha de 45 dias, isso é muita coisa. (Entrevista 12, 2019)

Além das incertezas quanto aos procedimentos, os atores também divergiram quanto à efetividade da estratégia de anúncios pagos. Três dos entrevistados colocaram a questáo desta maneira: 
... patrocinar é uma bola de ferro, gasta muito dinheiro para pouco resultado. Despenca alcance orgânico quando paga alguma coisa. $\mathrm{O}$ algoritmo entende que está disposto a pagar, entấo vou diminuir para um terço o alcance orgânico para ter que pagar. Então isso é o que começou a acontecer. Cada post básico tinha uma média de umas 600 curtidas, faltando um mês, por aí, passou para uns 200. Limitou a gente muito. (Entrevista 6, 2018)

Não víamos muito resultado em interação em geral, e eram investimentos muito altos. O seu melhor resultado é quanto menos consegue gastar por interaçăo. Tinha uma época que a gente conseguia gastar 10 centavos por curtida, isso é uma coisa bem em conta, é um investimento que vale a pena. Mas tinha umas coisas que a gente achava que ia dar muito certo e a gente gastava 1,50 , já chegou a 2 por curtida, um fracasso, a gente teve que cancelar. A gente conseguiu se preparar minimamente, para fazer uma escolha mais acertada, mas ao mesmo tempo era um teste recorrente. (Entrevista 27, 2019)

Impulsionar (conteúdo no Facebook) é bem mais complexo do que se imagina. A gente conseguiu achar a persona, o público alvo. Esse é o grande desafio. (Entrevista 9, 2018)

Aqueles candidatos que deixaram para começar a entender o processo de impulsionamento durante a campanha eleitoral demoraram muito para implementar. Outros acabaram por simplesmente não utilizar a ferramenta. A exceção é a candidatura do Deputado Donizet. Embora com parcos recursos a serem investidos, o então candidato decidiu empregálos exclusivamente no uso de ferramentas digitais, concentrando-se no impulsionamento de conteúdo via Facebook. Seria equivocado, no entanto, concluir a partir disso que qualquer candidato poderia ter utilizado a mesma estratégia e ser vitorioso. Ainda que a análise das causas do êxito das campanhas vá além dos objetivos deste artigo, é importante esclarecer que, no caso da campanha de Daniel Donizet, foi fundamental a sua associação estratégica às campanhas de Jair Bolsonaro, no nível nacional, e de Bia Kicis, candidata a deputada federal (também eleita). No Facebook, isto se refletiu na estratégia de segmentaçáo da audiência buscando atingir usuários que curtiam as páginas desses candidatos e na produção de conteúdo conjunto. ${ }^{14}$

\section{Consideraçóes Finais}

As tecnologias digitais vêm ganhando cada vez mais importância em processos eleitorais. Essa afirmação, ainda que verdadeira em termos gerais, precisa ser contextualizada e problematizada. Este artigo focou em um objeto de estudo ainda pouco explorado na literatura sobre eleiçóes no Brasil as escolhas de estratégias digitais em campanhas legislativas locais. Embora seja possível constatar uma tendência geral à digitalização das campanhas eleitorais, esse processo nâo é automático, não é linear e muito menos homogêneo.

A tipologia de estilos de campanhas digitais aqui apresentada contribui para os debates sobre estratégias digitais ao mapear as campanhas de acordo com a amplitude de usos de recursos digitais e dos gastos com propaganda digital paga. Ela permite, portanto, abarcar a heterogeneidade de práticas digitais que caracterizam processos eleitorais em geral, e as eleiçóes de 2018 em particular. Permite incluir tanto campanhas para as quais o impulsionamento de conteúdo online foi fundamental, como aquelas para as quais náo teve nenhuma relevância; permite incluir tanto campanhas que utilizaram apenas uma plataforma de mídia social para certos objetivos, como aquelas que buscaram maior amplitude de usos a partir de objetivos variados.

Embora a tipologia potencialmente sirva para a análise de outros casos, é preciso testá-la em diferentes contextos no Brasil e fora dele. É necessário advertir também que a excepcionalidade do caso estudado pode ser um elemento limitante do alcance das tendências gerais discutidas neste trabalho. Se, por um lado, não é possível estimar em que medida o caráter disruptivo das eleiçôes de 2018 determinou como os atores políticos incorporaram tecnologias digitais a suas campanhas, por outro, ficou claro 
que suas reações às mudanças nas possibilidades de uso das plataformas não foram afetadas apenas pelo acesso a recursos, mas, sobretudo, por como decidiram empregá-los. Daí a ênfase na compreensão do processo de apropriaçáo de tecnologia como um processo dinâmico de aprendizado dos atores em um contexto de incerteza quanto ao uso e à efetividade de novas estratégias digitais, incerteza essa que é uma característica intrínseca à inovação tecnológica, mas que foi potencializada pela falta de clareza das regras eleitorais.

Pesquisas futuras deverão analisar mais detidamente alguns dos resultados apresentados neste artigo. Por exemplo, merece uma pesquisa mais aprofundada o argumento de que o processo de apropriaçáo de recursos digitais durante as campanhas é relacional, no sentido de que é influenciado pela interação (presencial e digital) entre candidatos e membros da equipe de campanha e os eleitores. Essa interação adiciona mais um elemento de contingência e incerteza nos processos de apropriação de tecnologias em campanhas eleitorais, com os quais candidatos e suas equipes deverão aprender a lidar.

\section{AGRADECIMENTOS}

Os autores agradecem Thawany Gomes pelo trabalho de assistência de pesquisa, Emerson Rocha, pelas sugestôes para a construção dos índices apresentados neste artigo, e Kleber Chagas, pela ajuda com o contato dos entrevistados. Também agradecem as críticas e sugestóes dos pareceristas, assim como a leitura atenta dos membros do grupo de pesquisa Resocie (Repensando as Relaçóes entre Sociedade e Estado), do Instituto de Ciência Política da UnB, e o apoio do Instituto da Democracia e da Democratização das Comunicaçóes, projeto financiado pela CAPES, CNPq e FAPMIG. Agradecimento especial vai para os entrevistados e entrevistadas que aceitaram colaborar com a pesquisa. Marisa von Bülow agradece o apoio da bolsa da FAP-D.F., que permitiu que, durante a escrita deste artigo, estivesse filiada como pesquisadora junto ao German Institute for Global and Area Studies (GIGA) e ao Instituto de Ciências Sociais (ICS) da Universidade de Lisboa.

\section{Notas}

1 Por exemplo, Pippa Norris (2000) propôs diferenciar campanhas eleitorais pré-modernas, modernas e pós-modernas. Farrell e Webb (2002), similarmente, identificam três estágios consecutivos de desenvolvimento técnico das campanhas eleitorais (estágio 1, 2 e 3).

2 Vai além dos objetivos deste artigo a revisão da longa tradição de discussão na ciência política sobre os impactos da incerteza na formaçâo de preferências dos eleitores e na democracia (mas ver, por exemplo, Alvarez e Franklin, 1994; Ferejohn e Noll, 1978).

3 Os(as) entrevistados(as) desta pesquisa foram unânimes em minimizar a importância da participação no programa eleitoral gratuito da televisão e rádio nas suas campanhas, devido ao pouco tempo de exposiçãa.

4 São 24 cadeiras de deputados(as) distritais, mas neste artigo incluímos todas as candidaturas exitosas, que são 25 porque, após eleito, Francisco Fernandes foi convidado para ser administrador regional de Ceilândia. Assumiu a sua vaga a deputada Telma Rufino. Ambos foram incluídos nesta pesquisa.

5 Atores-chave, nesta pesquisa, eram os membros da campanha (candidatos(as) e assessores) que tinham conhecimento sobre as estratégias digitais utilizadas e participaram dos processos decisórios sobre as estratégias de campanha. Entrevistamos pelo menos um representante de cada uma das campanhas vitoriosas. A maior parte do total de 27 entrevistas foi presencial, e realizada com mais de um ator ao mesmo tempo, por exemplo com o(a) parlamentar e um(a) assessor(a). As entrevistas foram anônimas, conforme consentimento assinado pelos(as) entrevistados(as) para uso acadêmico do material.

6 Existe uma ampla literatura que discute as vantagens e limitaçóes do uso de entrevistas qualitativas e as estratégias que podem ser usadas pelos pesquisadores para minimizar as limitações intrínsecas à técnica. Uma das críticas mais importantes refere-se ao que Jerolmack e Khan (2014) denominaram de "falácia atitudinal", ou seja, a tendência de pesquisadores a fazerem uma equivalência entre o que é dito pelos atores e o que estes realmente fazem.

7 Dados do Tribunal Regional Eleitoral, disponíveis em http://www.tre-df.jus.br/imprensa/noticias-tre-df/2018/ Agosto/tre-df-divulga-numero-de-candidatos-registradosno-distrito-federal. 
8 http://www.tse.jus.br/imprensa/noticias-tse/2018/ Agosto/eleicoes-2018-divulgacandcontas-ja-registra27-6-mil-pedidos-de-candidatura

9 Ver o texto da lei, disponível em http://www.planalto. gov.br/ccivil_03/leis/L9504.htm

10 O Facebook faz a distinção entre impulsionamento via promoção de publicaçôes e a criação de um anúncio pago (ver as explicaçôes em https://www.facebook.com/ business/help/317083072148603, acessado em 23 de agosto de 2020). Os(as) entrevistados(as) relataram que fizeram anúncios, utilizando o Gestor de Anúncios da plataforma para segmentar o público.

11 Dos 513 deputados(as) eleitos, 256 declararam à justiça eleitoral a contratação de despesas com impulsionamento de conteúdo, em valor correspondente a 1,3\% dos gastos totais das campanhas (Kira et al., 2018, p. 6). Entre as campanhas que declararam despesas com impulsionamento, 174 gastaram menos de $5 \%$ das suas despesas totais com impulsionamento, enquanto apenas 10 deles direcionaram mais de $20 \%$ do total de despesas contratadas com impulsionamento de conteúdo (Kira et al, 2018, p. 12).

12 O índice de priorizaçáo de gastos com campanha digital resulta da divisão entre as despesas com impulsionamento de conteúdo na Internet (Facebook, Instagram e Google) e o total de despesas financeiras de campanha declarado por cada candidato(a) à Justiça Eleitoral, de acordo com a seguinte equaçáo: $I p=\frac{D i}{D f}$

Onde: I $\mathrm{p}$ = índice de priorizaçấo de gastos com campanha digital $\mathrm{Di}=$ despesa com impulsionamento de conteúdo na Internet $\mathrm{Df}=$ total de despesas financeiras de campanha declarado à Justiça Eleitoral

13 O índice de amplitude consiste na média dos graus de relevância do uso de dez tecnologias digitais para cinco objetivos de campanha, de acordo com atribuiçôes feitas pelos entrevistados sobre como usaram as tecnologias digitais em suas campanhas (ver Tabela 2). Essa medida é resultado da seguinte equação:

$I_{a}=(1 / 50) \sum_{j=1}^{5} \sum_{i=1}^{10} x_{i j}$

Onde: $\mathrm{Ia}=$ índice de amplitude de usos de tecnologias digitais

$\mathrm{j}$ = objetivos de campanha

$\mathrm{i}=$ tecnologias digitais empregadas

$\mathrm{X}_{i j}$ = relevância atribuída pelo candidato para a tecnologia i perante o objetivo $j$

14 Para um exemplo de anúncio conjunto publicado no Facebook por Bia Kicis e Daniel Donizet, ver https://www. facebook.com/biakicisoficial/videos/294277357872564.

\section{BIBLIOGRAFIA}

ABRANCHES, Sérgio. (2019), "Polarização radicalizada e ruptura eleitoral", in: Democracia Em Risco? 22 Ensaios Sobre o Brasil Hoje. Companhia das Letras, São Paulo, Brazil, 11-24.

AGGIO, Camilo. (2010), "Campanhas online: o percurso da formação das questóes, problemas e configuraçōes a partir da literatura produzida entre 1992 e 2009". Opinião Pública 16, 2: 426-445.

ALVAREZ, Michael R. \& FRANKLIN, Charles H. (1994), "Uncertainty and political perceptions," The Journal of Politics 56, 3: 671-688. https:// doi.org/10.2307/2132187

BARASSI, Veronica; TRERÉ, Emiliano. (2012), "Does Web 3.0 come after Web 2.0? Deconstructing theoretical assumptions through practice". New Media \& Society 14, 8: 1269-1285.

BARRETO, Leonardo. (2013), "O voto para deputado distrital: como o candidato escolhe seu eleitor" (Tese de Doutorado). Universidade de Brasília. Instituto de Ciência Política, Brasília, DF.

BLYTH, Mark. (2010), "Ideas, uncertainty, and evolution”, in: D. Béland \& R. H. Cox (orgs.), Ideas and Politics in Social Science Research, Oxford, Oxford University Press, p. 89-101.

BRAGA, Sérgio \& CARLOMAGNO, Márcio. (2018), "Eleiçôes como de costume? Uma análise longitudinal das mudanças provocadas nas campanhas eleitorais brasileiras pelas tecnologias digitais (1998-2016)". Revista Brasileira de Ciência Politica 26, 7-62. https://doi.org/10.1590/0103335220182601.

BRAGA, Sérgio; NICOLÁS, Maria Alejandra; BECHER, André Roberto. (2013a), "Clientelismo, internet e voto: personalismo e transferência de recursos nas campanhas online para vereador nas eleiçōes de outubro de 2008 no Brasil". Opiniāo Pública 19, 1: 168-197. https://doi.org/10.1590/ S0104-62762013000100008.

BRAGA, Sérgio; NICOLÁS, Maria Alejandra; BECHER, André Roberto. (2013b), "Elites políticas e novas tecnologias: uma análise do uso da internet pelos candidatos aos governos estaduais e ao senado nas eleiçôes brasileiras de outubro de 2010”. In: F. J. Marques; R. C. 
Sampaio; C. Aggio. (Orgs.). Do clique à urna: internet, redes sociais e eleiçóes no Brasil. Salvador: UFBA, p. 371-421.

BRAGA, Sérgio. (2014), "O Uso das Mídias Sociais é Um Bom Preditor do Sucesso Eleitoral dos Candidatos? Uma análise das campanhas online dos vereadores das capitais das regióes sul, sudeste, e nordeste do Brasil no pleito de outubro de 2012”. Revista Politica Hoje, 22: 125-148.

BRITO CRUZ, Francisco (coord.); MASSARO, Heloísa; OLIVA, Thiago; BORGES, Ester. (2019a), Internet e eleiçôes no Brasil: diagnósticos e recomendaçóes. Internet Lab, São Paulo.

BRITO CRUZ, Francisco; MASSARO, Heloísa; BORGES, e Ester. (2019b), "O custo da propaganda eleitoral paga na Internet em 2018”, InternetLab, disponível em: https://www.internetlab.org.br/ $\mathrm{pt} /$ informacao-e-politica/o-custo-da-propagandaeleitoral-paga-na-internet-em-2018/, consultado em 20/8/2020.

CASTILLO, Gil. (2018), "Brasil 2018: la elección radicalizada", in: A. Arrellano (org.), Nuevas Campañas Electorales en América Latina. Konrad Adenauer Stiftung, Montevideo, Uruguai, 69-80.

CESARINO, Letícia. (2020), "Como vencer uma eleição sem sair de casa: a ascensão do populismo digital no Brasil”. Internet \& Sociedade, 1, 1: 91-120.

CHADWICK, Andrew. (2017), The hybrid media system: politics and power, Second Edition, Oxford University Press, New York, NY.

DOMMETT, Katharina; POWER, Sam. (2019), "The political economy of Facebook advertising - election spending, regulation, and targeting online”. The Political Quarterly, 90, 2: 257-265.

EVANGELISTA, Rafael; BRUNO, Fernanda. (2019), "WhatsApp and political instability in Brazil: targeted messages and political radicalisation". Internet Policy Review, 8, 4. doi: 10.14763/2019.4.1434.

FARRELL, David \& WEBB, Paul. "Political parties as campaign organizations”. In: Dalton, R. e Wattenberg, M. (orgs.) Parties without Partisans: Political change in advanced industrial democracies. Oxford: Oxford University Press, 2002, p. 102-128.
FEREJOHN, John; NOLL, Roger. (1978), "Uncertainty and the Formal Theory of Political Campaigns". The American Political Science Review, 72, 2: 492-505. doi:10.2307/1954106.

FLYVBJERG, Bent. (2006), "Five misunderstandings about case-study research". Qualitative Inquiry, 12, 2: 219-245.

GERBAUDO, Paolo. (2012), Tweets and the Streets: social media and contemporary activism, London, Pluto Press.

GOMES, Wilson; FERNANDES, Breno; REIS, Lucas; SILVA, Tarcizio. (2009), " 'Politics 2.0': a campanha online de Barack Obama em 2008”. Revista de Sociologia e Politica 17, 34: 29-43. https:// doi.org/10.1590/S0104-44782009000300004.

GULATI, Girish; WILLIAMS, Christine. (2013), "Social Media and Campaign 2012: Developments and Trends for Facebook Adoption". Social Science Computer Review 31: 577-588. https:// doi.org/10.1177/0894439313489258.

IBGE. (2018), Acesso à Internet e à televisão e posse de telefone móvel celular para uso pessoal PNAD Contínua 2018 - Análise dos Resultados, disponível em ibge.gov.br.

JASPER, James. (2004), "A strategic approach to collective action: Looking for agency in social movement choices". Mobilization, 9, 1: 1-16.

JEROLMACK, Colin; KHAN, Shamus. (2014), "Talk is Cheap: ethnography and the attitudinal fallacy”. Sociological Methods \& Research, 43, 2: 178-209.

KIRA, Beatriz; MASSARO, Heloisa; CRUZ, Francisco Brito. (2018), "A campanha política nas redes: um retrato do impulsionamento de conteúdo das candidaturas eleitas à Câmara dos Deputados”, Relatório 3, InternetLab, São Paulo.

MARQUES, Francisco; MONT'ALVERNE, Camila. (2016), "How Important is Twitter to Local Elections in Brazil? A Case Study of Fortaleza City Council”. Brazilian Political Science Review 10, 3: 1-35. https://doi.org/10.1590/198138212016000300005.

MARQUES, Francisco; MONT'ALVERNE, Camila. (2013), "Twitter, eleiçóes e poder local: um 
estudo sobre os vereadores de Fortaleza". Revista de Comunicação e Cultura 11, 2: 322-347.

NEMER, David. (2019), "A radicalização invisível da direita no WhatsApp", Huffington Post, https:// www.huffpostbrasil.com/entry/whatsapp-bolsonaro_ br_5d5b5487e4b0d1e11366e0a9? guccounter=1.

NORRIS, Pippa. (2000), A virtuous circle: political communications in postindustrial societies, Cambridge University Press, Cambridge.

PRZEWORSKI, Adam. (1991), Democracy and the Market: political and economic reforms in Eastern Europe and Latin America, Cambridge: Cambridge University Press.

SAMPAIO, Rafael; BOZZA, Gabriel; ALISON, Murilo; MARIOTO, Djiovanni; BORGES, Tiago (2020), "Instagram e eleiçóes: análise dos stories dos candidatos à Presidência do Brasil em 2018". Animus, 19, 41.

SANTOS, Joāo; FREITAS, Miguel; ALDÉ, Alessandra; SANTOS, Karina; CUNHA, Vanessa. (2019), "WhatsApp, política mobile e desinformação: a hidra nas eleiçōes presidenciais de 2018". Comunicação \& Sociedade, 41, 2: 307-334.

STROMER-GALLEY, Jennifer. (2014), Presidential Campaigning in the Internet Age. Oxford University Press. https://doi.org/10.1093/ acprof:oso/9780199731930.001.0001.

TSE. (2017), Resolução 23.551, Brasília: Tribunal Superior Eleitoral.

VON BÜLOW, Marisa; VILAÇA, Luiz; ABELIN, Pedro Henrique. (2019), "Varieties of digital activist practices: students and mobilization in Chile". Information, Communication \& Society, 22, 12: 1770-1788. https://doi.org/10.1080/1 369118X.2018.1451550.

WILLIAMS, Christine; GULATI, Girish. (2013), "Social networks in political campaigns: Facebook and the congressional elections of 2006 and 2008". New Media \& Society 15, 52-71. https:// doi.org/10.1177/1461444812457332.

\section{ENTREVISTAS}

Entrevista 1. Entrevista realizada com assessora parlamentar. Entrevistadores: Marisa von Bülow e Igor Brandão, 8 de novembro de 2018, Brasília.

Entrevista 5. Entrevista realizada com parlamentar. Entrevistadora: Marisa von Bülow, 22 de novembro de 2018, Brasília.

Entrevista 6. Entrevista realizada com assessor parlamentar. Entrevistadora: Marisa von Bülow, 22 de novembro de 2018, Brasília.

Entrevista 8. Entrevista realizada com parlamentar e assessores. Entrevistadores: Marisa von Bülow e Igor Brandão, 4 de dezembro de 2018, Brasília.

Entrevista 9. Entrevista realizada com parlamentar. Entrevistadora: Marisa von Bülow, 12 de dezembro de 2018, Brasília.

Entrevista 12. Entrevista realizada com parlamentar. Entrevistadores: Marisa von Bülow e Igor Brandáo, 8 de novembro de 2018, Brasília.

Entrevista 13. Entrevista realizada com parlamentar e uma assessora. Entrevistadores: Marisa von Bülow e Igor Brandáo, 12 de dezembro de 2018, Brasília.

Entrevista 26. Entrevista realizada com parlamentar e uma assessora. Entrevistadora: Marisa von Bülow, 11 de março de 2019, Brasília.

Entrevista 27. Entrevista realizada com parlamentar e uma assessora. Entrevistadores: Marisa von Bülow e Igor Brandão, 12 de março de 2019, Brasília. 


\section{O QUADRANTE VAZIO: ESTILOS DE CAMPANHAS ELEITORAIS DIGITAIS NAS ELEIÇÓES PARA DEPUTADOS DISTRITAIS EM 2018}

\section{Marisa von Bülow, Igor Brandáo}

Palavras-chave: eleiçôes; estratégias digitais; Câmara Legislativa do Distrito Federal; campanhas eleitorais; mídias sociais; internet

Este artigo mapeia e analisa as estratégias eleitorais digitais utilizadas pelos (as) deputados (as) distritais eleitos em 2018 no Distrito Federal. Com base em entrevistas qualitativas, análise de documentos e análise de dados de gastos de campanhas, propóe uma tipologia de quatro estilos de campanhas eleitorais digitais. A análise mostra que, pese à crescente relevância das tecnologias digitais em campanhas eleitorais, um quadrante permanece vazio: o das campanhas que priorizam gastos com impulsionamento de conteúdo online ao mesmo tempo em que utilizam uma grande diversidade de plataformas digitais. $\mathrm{O}$ artigo argumenta que as práticas adotadas resultam de processos dinâmicos de aprendizado dos atores em um contexto de incerteza quanto ao uso e à efetividade de novas estratégias digitais. Argumenta também que esses processos são relacionais, no sentido de que a incorporação de tecnologias é em parte fruto da interação com os eleitores, que pressionam os candidatos a ter maior presença digital.

\section{THE EMPTY QUADRANT: STYLES OF DIGITAL ELECTORAL CAMPAIGNS IN ELECTIONS FOR DISTRICT DEPUTIES IN 2018}

\section{Marisa von Bülow, Igor Brandáo}

Keywords: elections, digital strategies, Legislative Chamber of the Federal District, electoral campaigns, social media, Internet

This article maps and analyzes the digital electoral strategies used by district deputies elected in 2018 in the Federal District. Based on qualitative interviews, document analysis and analysis of campaign spending data, it proposes a typology of four digital election campaign styles. The analysis shows that, despite the growing relevance of digital technologies in election campaigns, one quadrant remains empty: that of campaigns that prioritize spending on boosting online content while using a wide variety of digital platforms. The article argues that the practices adopted result from dynamic learning processes by the actors in a context of uncertainty regarding the use and effectiveness of new digital strategies. It also argues that these processes are relational, in the sense that the incorporation of technologies is in part the result of interaction with the voters, who pressure the candidates to have a greater digital presence.

\section{LE QUADRANT VIDE: STYLES DE CAMPAGNES ELECTORALES NUMERIQUES LORS DES ELECTIONS DE DEPUTES DU DISTRICT FEDERAL EN 2018}

Marisa von Bülow, Igor Brandáo

Mots-clés: élections, stratégies numériques, chambre législative du District fédéral, campagnes électorales, médias sociaux, internet.

Cet article présente et analyse les stratégies électorales numériques utilisées par les députés du District Fédéral élus en 2018. Sur la base d'entretiens qualitatifs, de l'examen de documents et des dépenses de campagne, il propose une typologie de quatre styles de campagne numérique. Malgré l'importance croissante des technologies dans les campagnes électorales, un quadrant reste vide: celui des campagnes qui donnent la priorité aux dépenses pour les contenus en ligne tout en utilisant une grande variété de plateformes numériques. L'article montre que les pratiques adoptées résultent de processus d'apprentissage dynamique des acteurs dans un contexte d'incertitude quant à l'utilisation et à l'efficacité des nouvelles stratégies numériques. Il soutient également que ces processus sont relationnels, en ce sens que l'incorporation des technologies est en partie le résultat d'une interaction avec les électeurs, qui font pression sur les candidats pour une plus grande présence numérique. 